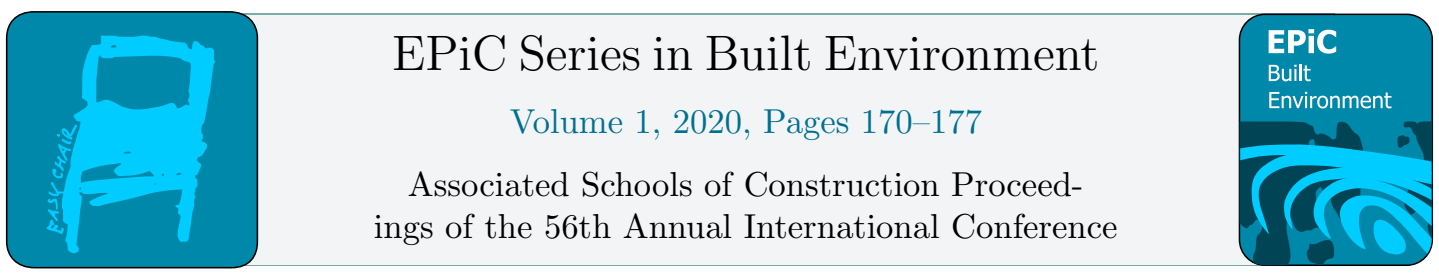

\title{
Initial Student Perception of the Benefits of Participation on an International ASC Competition Team
}

\author{
Heather Yates, EdD \\ Oklahoma State University \\ Stillwater, OK
}

\author{
Blake Wentz, PhD \\ California State University, Chico \\ Chico, CA
}

\author{
Sreemala DasMajumder \\ Oklahoma State University \\ Stillwater, OK
}

The construction industry is becoming more diverse and global in terms of the project workforce. There is a significant need for universities to provide educational opportunities for students in order to prepare them to operate in a global market. Currently, there are limited opportunities to gain an international experience in construction management programs in the U.S., with most being limited to a study abroad program. But the advent of the International ASC Student Competitions has opened new opportunities for students to engage in a collaborative team and gain exposure to internationalization in construction. This paper surveyed students from two such teams to determine their perceptions of the experience, with all students indicating the benefits far outweigh the challenges of being on such a team. These initial perceptions point to further study the significance of these international competition teams in terms of increasing student experiences abroad.

Key Words: Global; International Collaboration; Study Abroad; Student Experiences; Student Competition

\section{Introduction}

In the age of globalization, many U.S. employees are expected to collaborate with colleagues from around the world. Globalization has affected the construction industry as U.S. companies continue to work around the world and various related services are globally outsourced. It has also been noted that U.S. construction companies are experiencing an influx of foreign-born workers requiring construction managers to deal with issues involving a more diverse workforce (Lower \& Shaurette, 2010). As the construction industry has broadened both domestically and abroad, the academic institutions, engineering professionals, and the corporate organizations continue to benefit from the commercial and corporate advantages that can be obtained from an educated, well-organized multicultural team with international context (Bradner \& Mark, 2002). 
Advancement in communication and information technologies have accelerated the possibility of international collaboration practices (Friedman, 2005). Because of this trend, global competition in construction has increased when compared to other industries. The globalization of construction has led to the formulation of multinational teams, international alliances, cross-national outsourcing and bidding practices, along with the employment of foreign employees (Quinones, Fussell, Hall, Soibelman, \& Akinci, 2009). Industry internationalization has been accompanied by revolutionary changes in management engineering practices and eventually the multicultural collaborative teams (Doerry, Doerry, \& Bero, 2003).

Because of the trend of globalization in the construction industry, it is important that universities prepare students to encounter this in their professional lives. There are several different methods that this can be accomplished, such as classroom instruction, study abroad programs, international field trips, and international cooperation via competition teams. The Associated Schools of Construction (ASC) offers several different competitions that are open to teams that are combined between two universities, one based in the U.S. and the other is a non-U.S. school. This study looks to survey the participants on these teams to see the perception of the students on their international problem-solving experience.

\section{Literature Review}

It has been recognized that the ability to adapt to diverse situations for a construction or engineering professional for international and multicultural teams is crucial. Engineering professionals have difficulty in understanding and recognizing differences and lack cross-cultural social, technical and managerial skills. Their techniques, communication, collaboration and teamwork skills are often best suited for domestic practice (Fruchter, 2001). Researchers have suggested that proper communication, teamwork and professional ethics are equally important subjects for engineers to know (Zitomer, Gabor, \& Johnson, 2003).

Several construction projects are performed by geographically dispersed multinational teams characterized by different knowledge and skill levels, diverse cultural backgrounds, as well as linguistic boundaries. These factors along with unique groups of people as well as the complex nature of international construction sites make it difficult for construction professionals to communicate, collaborate and coordinate information in order to deliver a project. In order to be successful, employees need socio-economic knowledge along with engineering knowledge (Cheah, Chen, \& Ting, 2005). Research shows the importance of cross-cultural communication and collaboration skills as crucial factors influencing the diverse teams (Brien, Soilbelman, \& Elvin, 2003).

With the expansion of the global economy, universities have shown interest in including global experiences in the higher education curriculum (Shaurette, 2014). There are many challenges noted that have limited international experiences in higher education. Shaurette (2014) highlights "resistance to change, time constraints" and "constraints when working across geographic boundaries" as challenges faced by universities when adding international components to the curriculum. Throughout the literature there is growing acknowledgement that changes in higher education are needed to promote global competencies and international experiences (El Debs, Brunese, \& Shaurette, 2018). Global experiences for students can be fulfilled through many different international education and collaborative involvements.

\section{International Educational \& Collaborative Experiences}


Knowing that engineering and construction engineering students need more international exposure, a handful practices are prevalent in U.S. like traditional study abroad programs, distance learning to provide some experience. Such efforts are aimed to encourage students to participation, but, less than $2 \%$ of U.S engineering students partake in such programs. Potential international opportunities through higher education include study abroad programs, faculty led courses while traveling internationally, international internships, and international design projects (Warnick, 2011). The advancement of technology has provided opportunities for students to get international experiences without leaving the U.S. and can enhance a shorter-term experience outside of the country by providing opportunities to collaborate before and after the international trip. International student competitions are international design projects that combine the collaboration of students from different countries and depend upon distance education for students to collaborate before the international event.

\section{Study Abroad Programs}

Upwards of 670,000 students enter the U.S. as international students, whereas only 262,000 U.S. students leave to study abroad. While 41 percent of the internationals students in the U.S. are studying in STEM fields, the U.S. study abroad STEM students only account for 16 percent of the outflow population (Goodman \& Gutierrez, 2011). Engineering schools across the United States are conducting exemplary programs to send students for a semester or more overseas (Jones \& Oberst, 1997). Some universities have made it a major requirement for each student to participate in an international project prior graduation. Due to the concentrated efforts the number of students graduating with international educational experiences are increasing.

Traditional study abroad programs typically last a year or longer, especially when describing the experiences of international students entering the U.S. as many of these students are pursuing a full degree from a university. However, U.S. students going abroad normally opt for shorter durations of a semester or even less. Recently, programs lasting 8 weeks or less have been coined "short-term" international study abroad programs (Goodman \& Gutierrez, 2011). Two to three-week faculty led courses while traveling abroad could also be considered short term study abroad experiences. These shorter-term programs have increased in popularity providing opportunities for a larger group of students who may not typically be able to participate due to time, money, or other challenges.

Another option for students is to participate in an international internship. International internships provide a means for addressing the need for globally minded STEM professionals. Yet few higher education institutions have established such programs or have strong mechanisms for integrating them into the curriculum (Donohue \& Altaf, 2012). According to the 2011 IIE Open Doors Report on International Educational Exchange, only 3.9 percent of U.S. students who received credit for study or work abroad were engineers (Bezrukov \& Ziyatdinova, 2014).

\section{Distance Education}

Electronic tools and media have used extensively by students and faculty members to work in groups on campus or miles apart. As technology has advanced, collaboration in real time over long distances can be seamless. The advanced use of multimedia and communication mechanisms allow faculty to teach engineering design across boarders (Hsi and Agogino, 1994). The use of internet is one of the most powerful tools to acquire knowledge and easily pass on to students defeating boundaries. Smart 
information technologies are used to teach multi-site, project centered, team-oriented courses (Fruchter, 2001).

A handful of engineering programs in the U.S are currently using distance learning techniques to give students the experience of international exposure. Such programs are operated in the University of Washington, Texas A\&M University, the University of Pittsburgh (Bucinell, Kenyon, Erden, \& Platin, 2002). In this research it stated, "The ever-increasing globalization of engineering practice has led to the realization that undergraduate students must be aware of the global nature of the profession and the technologies that allow engineers the world over to collaborate on projects". Union College engineering students can study a semester in an international exchange program or be a part of an international project. Using electronic media and internet students from Union College and Middle East Technical University (METU) came together and developed a single design and constructed the project sharing data and designs electronically as described by (Bucinell et al., 2002). The members of the team met each other at the end of the project when they came together for the assembly of their final design.

\section{Barriers Associated with International Experiences}

Despite the importance of universities increasing the global competencies of students, many universities have not implemented strategies to expose the students to these areas because of significant barriers. Some of the challenges noted in the literature include resistance to change, time constraints, inflexible or incompatible reward systems, constraints created when working across geographic boundaries, limits to the use of active learning, limitations and continual changes in instructional technology, a diversity of views on and application of assessment, as well as limited international accreditation (El Debs et al., 2018).

Although there are several different opportunities for international experiences for students in construction management programs, the above listed barriers continue to keep participation low. But with student competitions in ASC becoming more and more prevalent, especially regions that offer the ability for teams to participate as part of a blended international team, these international collaborations are more readily available to students.

\section{Methodology}

In order to evaluate the perceptions of students regarding their specific international competition experience, both qualitative and quantitative data was collected. The survey questions were informed by two previous studies on project-based student collaboration within multinational teams (Quinones et al., 2009; Soibelman et al., 2011) study included a multinational team collaborating to produce construction project deliverables include a schedule, cost estimate, risk assessment, and bid document preparation. The deliverables described in the study are similar to what is asked of the students in the ASC Region 8 Student Competition.

Subjects for the survey were identified from the team rosters of students who competed in the ASC Region 8 and/or Region 5 international competitions in 2018 and 2019 respectively. The students were from two different teams that collectively were from four different universities, two from the United States, one from the UK, and one from Ireland. From this list a total of 12 subjects were identified and all were contacted via email to fill out the survey. Both the Region 8 and Region 5 student competitions require international teams to include fifty-percent of the team members to be from one university and the other fifty-percent from another university in a different country. 
The survey consisted of eight topical sections, each with multiple questions regarding the topic specified. The topical sections were:

- Communication

- Technical Skills

- Information Technology

- Roles and Responsibilities

- Time Perception

- Cultural Background

- Geographical / Time Zone Differences

- Overall Advantages

In each category, the students were asked open ended questions to elicit qualitative responses, followed by questions that asked students to rate their agreeance with the statement from strongly disagree to strongly agree on a 5-point Likert scale response. Due to the small number of participants, this preliminary study focused on the qualitative responses from the participants. The quantitative responses were used to reinforce themes and only considered when the responses reveled the consensus of the participants.

The survey was conducted with respondents replying via email. Of the twelve students contacted for this study, all twelve responded constituting a $100 \%$ response rate. The main purpose of the survey was to gain insight into students' perceptions of the international competition team experience.

The qualitative survey responses were analyzed for trends in order to determine the perceptions of the international competition experience, as well as to determine if further study is warranted on the subject with a larger set of participants. Additionally, the responses were compared to the results of the previous work in international project-based collaboration.

\section{Results}

The results of the communication section of the survey showed minimal issues encountered by the teams. Most respondents indicated that communication was done via email, skype, and collaborative tools such as Google docs before the competition phase. There were minor issues before the competition scheduling the collaboration sessions because of the time zone differences between the universities, but these were easily handled amongst the team members. Students indicated that there were not any linguistic barriers, which would be expected considering that English was the official language of all of the students surveyed. Students also reported that they did not encounter any additional communication issues as compared to what they have encountered on a domestic team.

In terms of technical skills, the students indicated that there was not a drastic learning curve for the competition, and that team members level of technical skills was comparative amongst all team members, and what they expect of their peers. The students' technical skills and problem-solving capabilities lead them to overcome a few IT challenges. The participants reported the IT played a greater role while working on an international team, than teams that they have been a part of during their university experience. Because the students were not all from the same university and were not all registered at one university or another, multiple participants reported having problems working collaboratively on documents through their traditional means like Microsoft One Drive. This lead to students learning about alternate collaborative technology like box.com. 
Also, the respondents indicated that the roles and responsibilities were similar between the different universities, and that assigning these was not an issue between team members. This was evident in terms of construction management skills such as estimating and scheduling, but where students responded they had difficulty was with the information technology and specific tools used in the competition. All students were proficient with Autodesk Revit for the design aspects of the competition, but some specific software for estimating was different between universities and required some quick learning.

\section{Challenges}

A significant challenge identified by the respondents was the time restraint of the competition. All of the ASC student competitions have time restrictions and the international competition has either an 8 hour or 16-hour problem solving window depending on whether the competition is hosted by Region 8 or 5 respectively. Most of the respondents listed this as a major concern, but time management was not listed as an issue for the teams. All team members were confident in their time management plans that were formulated by the team at the beginning. The perception of time and deadlines were similar among the international teams. This was accomplished through strong communication and cooperation between the team members.

Other notable challenges during the international competition experience included minor confusion with construction terminology. In the vein of differences in terminology, students also had some challenges moving back and forth from the metric system to the English feet and inches measurements as the competitions were held in both the U.S. and Europe. Interestingly, the student competition participants spent more time describing how they were like their international peers than outlining the differences. The members of the teams seemed to find their international counterparts very interesting.

\section{Advantages}

There were several advantages that were indicated by the respondents. One of the most common responses was the fact that because the students came from different countries, universities, and backgrounds, there were varying viewpoints on how work could be done, and this fostered more creativity in solving problems. Students were able to look at issues from different angles and they were able to pull from a more diverse set of experiences in order to come up with solutions. Many students indicated that this was the most fun part of working on an international team.

The experiences gained from hearing and learning about different construction methods, thought processes, and general work methodology helped develop a stronger work ability. Being able to work and learn from multiple disciplines throughout the competition nurtured overall knowledge of how architecture and engineering can be implemented on a project. Overall the respondents thought the advantages of working on an international team far outweighed the challenges faced by the team. All in all, one hundred percent of the participants found it advantageous to have the experience on an international team.

\section{Recommendations and Conclusion}

The results show that the participation on the ASC international competition team had a profound impact on the students. Respondents indicated that the competition was challenging not only for the technical component of the competition, but culturally as well. Students felt that their learning and 
problem-solving abilities were enhanced through the differences in experiences and problem solutions among the team members. Adding to the experience was the intrigue of the cultural differences among their teammates, which in turn brings more value to the experience. All international experiences are valuable, but the opportunity to collaborate in an international problem-based learning experience enhanced the student learning and appreciation for other cultures.

Future research in this area can be done to determine if these conclusions are consistent for students across all participants in the international ASC competitions. The initial findings from these teams indicate strong opinions of the value of the international competition experience on their future careers and expanding this study could add to the body of knowledge on student international experiences. The survey used could be further developed to incorporate more quantitative data so that statistical analysis can be used in order to determine if any correlation exists between the international ASC competitions and students global view of the construction industry.

The two main factors that restrict the ability of students to participate in other international experiences such as study abroad programs are the time and financial commitments. The ASC international competitions are perfect solutions to this issue by minimizing both the time and money needed by the students in order to participate. Although the time spent at the actual competition is small in comparison to a semester abroad, the time spent preparing using digital technology leads to the students to gaining more professional knowledge, increase their problem-solving skills, and obtaining a broader cultural perspective to the construction industry.

\section{References}

Bezrukov, A., \& Ziyatdinova, J. (2014, December). Internationalizing engineering education: A language learning approach. In 2014 International Conference on Interactive Collaborative Learning (ICL) (pp. 299-302). IEEE.

Bradner, E., \& Mark, G. (2002, November). Why distance matters: effects on cooperation, persuasion and deception. In Proceedings of the 2002 ACM conference on Computer supported cooperative work (pp. 226-235). ACM.

O’Brien, W., Soibelman, L., \& Elvin, G. (2003). Collaborative design processes: an active-and reflective-learning course in multidisciplinary collaboration. Journal of Construction Education, 8(2), 78-93.

Bucinell, R. B., Kenyon, R. A., Erden, A., \& Platin, B. E. (1997, November). The international virtual design studio. In Proceedings Frontiers in Education 1997 27th Annual Conference. Teaching and Learning in an Era of Change (Vol. 2, pp. 821-826). IEEE.

Cheah, C. Y., Chen, P. H., \& Ting, S. K. (2005). Globalization challenges, legacies, and civil engineering curriculum reform. Journal of Professional Issues in Engineering Education and Practice, 131(2), 105-110.

Doerry, E., Doerry, K., \& Bero, B. (2003). The global engineering college: Exploring a new model for engineering education in a global economy. In American Society for Engineering Education Annual Conference Proceedings (pp. 1-13).

Donahue, D. G., \& Altaf, S. (2012). Learn by Doing: Expanding International Internships/Work 
Abroad Opportunities for US STEM Students. Institute for International Education.

El Debs, L. C., Brunese, P. S., \& Shaurette, M. (2018). Use of Concept Maps to Illustrate Barriers to Construction Industry Inter-Organizational Communication: a Comparative View from Students and Professionals. International Journal of Construction Education and Research, 14(2), 77-94.

Friedman, T. L. (2005). The world is flat: A brief history of the twenty-first century. Macmillan.

Fruchter, R. (2001). Dimensions of teamwork education. International Journal of Engineering Education, 17(4/5), 426-430.

Goodman, A. E., \& Gutierrez, R. (2011). The international dimension of US higher education: Trends and new perspectives. In International students and global mobility in higher education (pp. 83106). Palgrave Macmillan, New York.

Hsi, S., \& Agogino, A. M. (1994). The impact and instructional benefit of using multimedia case studies to teach engineering design. Journal of Educational Multimedia and Hypermedia, 3(34), 351-376.

Jones, R. C., \& Oberst, B. S. (1997). International Experience for Engineering Students through Distance Learning Techniques, 98(2).

Lower, J., \& Shaurette, M. (2010). Students' Knowledge of Instructors and its Impact on Student Motivation. In American Society for Engineering Education. American Society for Engineering Education.

Quinones, P. A., Fussell, S. R., Soibelman, L., \& Akinci, B. (2009, February). Bridging the gap: discovering mental models in globally collaborative contexts. In Proceedings of the 2009 international workshop on Intercultural collaboration (pp. 101-110). ACM.

Shaurette, M. (2014). International Collaboration : An Emergent Opportunity in Construction Management Education.

Soibelman, L., Sacks, R., Akinci, B., Dikmen, I., Birgonul, M. T., \& Eybpoosh, M. (2010). Preparing civil engineers for international collaboration in construction management. Journal of Professional Issues in Engineering Education and Practice, 137(3), 141-150.

Warnick, G. M. (2011). AC 2011-350: Global Competence: Its Importance for Engi-Neers Working a Global Environment. In American Society for Engineering Education.

Zitomer, D. H., Gabor, M., \& Johnson, P. (2003). Bridge construction in Guatemala: Linking social issues and engineering. Journal of Professional Issues in Engineering Education and

Practice, 129(3), 143-150. 